Publications on serological tests for syphilis serology are littered with initials and acronyms, and there may be more to come. The enzyme-linked immunosorbent assay ${ }^{7}$ (ELISA) has been shown in preliminary studies to be relatively quick and simple, equivalent in specificity to the fluorescent antibody (absorbed) test, but more work is needed before it can be brought into routine clinical practice. The same may be said of the solid-phase haemadsorption test for $\operatorname{IgM}$ antibodies, which has recently been developed. ${ }^{8}$ Some workers have reported that the test is highly specific for $\operatorname{IgM}$ antibodies to $T$ pallidum, easy to do, and inexpensive ${ }^{9}$; others have found that the test is unreliable in comparison with other tests for $\operatorname{IgM}$ antibodies. ${ }^{6}$

Reagin tests seem likely to continue to be generally used in the foreseeable future, with increased use being made of automated procedures for both reagin and specific tests. Nevertheless, it is as true today as it was in 1906 that the accurate diagnosis of syphilis, though greatly helped by laboratory aids, is ultimately based on a thorough history and clinical examination.

Consultant Physician

Department of Genitourinary Medicine,

University College Hospital,

London WC1E 6AU

' Wilkinson AE, Taylor CED, McSwiggan DA, Turner GC, Rycroft JA, Lowe GH. Laboratory diagnosis of venereal disease. London: HMSO, 1972. (Public Health Laboratory Service Board, Monograph Series, No 1.)

2 Stokes EJ, Ridgway GL. Clinical immunology. Clinical bacteriology. 5th ed. London: Edward Arnold, 1980:274-83.

${ }^{3}$ Catterall RD. Systemic disease and the biological false positive reaction. Br $\mathcal{F}$ Vener Dis 1972;48:1-12.

4 Sequeira PJL, Eldridge AE. Treponemal haemagglutination test. $\mathrm{Br} \mathcal{F}$ Vener Dis 1973;49:242-8.

${ }^{5}$ O'Neill P. A new look at the serology of treponemal disease. Br $\mathcal{F}$ Vener Dis $1976 ; 52: 296-9$.

${ }^{6}$ Müller F, Lindenschmidt E-G. Demonstration of specific 19S(IgM) antibodies in untreated and treated syphilis. Comparative studies of the 19S(IgM)-FTA test, the 19S(IgM)-TPHA test, and the solid phase haemadsorption assay. Br $\mathcal{F}$ Vener Dis $1982 ; 58: 12-7$.

7 Veldkamp J, Visser AM. Application of the enzyme-linked immunosorbent assay (ELISA) in the serodiagnosis of syphilis. Brf Vener Dis 1975; $51: 227-31$.

${ }^{8}$ Schmidt BL. Solid-phase hemadsorption: a method for rapid detection of Treponema pallidum-specific IgM. Sex Transm Dis 1980;7 :53-8.

${ }^{9}$ Luger A. Diagnosis of syphilis. Bull WHO 1981;59:647-54.

\section{Image and reality: drugs for the future}

Pharmaceutical manufacturers share some of the characteristics of policemen and pawnbrokers; most people see them in blackand-white terms either as villains or as assets to our society. These polarised responses have become apparent recently in the public response to claims by the industry that new drugs cost so much to develop and take so long to test that innovation will soon no longer be cost effective. Certainly fewer new drugs are being marketed than 20 years ago-but might that not be simply because the drug explosion is over? Major innovations, such as $\mathrm{H}_{2}$-receptor antagonists as treatments for peptic ulcer, can still make vast profits for the companies concerned. Does it really matter if the flow of new diuretics, tranquillisers, and hypotensive drugs is slowing?

These questions were examined at a conference last month in Oslo organised by the Association of Norwegian Representatives of Foreign Pharmaceutical Manufacturers. Speakers were quick to assert that the current generation of drugs were the results of 15 to 20 years' gestation and that without some change the pace of innovation would continue to slow.

The clear message from the research units was that there was no shortage of new, promising areas for development. The genetic manipulation of bacteria, though still in its early stages, had already produced human growth hormone and human insulin, so solving the problems of short supply that had threatened to become major anxieties for clinicians. Monoclonal antibodies were revolutionising diagnostic techniques in the laboratory. More antiviral drugs and antiviral vaccines were being developed with greater specificity and less toxicity. Whole topics of pharmacological research, such as the prostacyclin-thromboxane system, were just yielding their first products for clinical assessment.

Yet the pessimistic assessment of Professor William Wardell, of Rochester, United States, was that these research efforts would produce few new drugs by the year 2000 . The possible exceptions were some cheap hormones made by genetic engineering and some modified interferons; the remainder of the research lines would, he thought, become delayed by the expense of laboratory and clinical testing. Certainly the companies based in the United States would produce fewer new clinical entities in the 1980s and 1990s than they had in the 1970s-despite the rapid recent advances in so many aspects of medical science.

This despondent assessment was not challenged by anyone at the conference. Critics of the pharmaceutical industry may point to its conspicuous affluence and its aggressive marketing techniques, but it is the only imaginable source of new drugs. Only half a dozen countries have an innovative pharmaceutical industry; the remainder are content to be free-riders. The poor image of the drug industry has encouraged several rich, technically advanced nations to legislate on costs, generics, and restricted formularies in such a way as to extinguish any possibility of their having a home-based industry.

Where does the future lie ? The cost quoted to the conference of developing a single new drug is now approaching $£ 100$ million-a figure accounted for partly by the cost of the thousands of potential new drugs that failed somewhere along the line and partly by the extended programme of tests required by government drug-regulatory agencies. These costs could be reduced if the six to nine years of clinical testing could be simplified. Another substantial but sensible reform would be for more countries to follow the Scandinavian example of harmonising their regulatory requirements so that companies need not go through a complex exercise for each country in turn. With such changes the effective patent life of new drugs would be extended to about 10 years instead of seven years or less, as at present.

Substantial changes in legislation on drug safety will depend, however, on changes in public attitudes. The '60s and '70s were the decades of consumerism, when governments seemed to believe that the voices of the professional consumers should be given more attention than those of patients and their doctors. Drugs were portrayed by investigative journalists as expensive, dangerous, and largely unnecessary. Such a picture was based on examples such as the use of tranquillisers as treatment for discontent, and it ignores the reality: every outpatient department is thronged with patients with chronic diseases for which current drugs are ineffective or have serious side effects or both. Our society does need new drugs; only the pharmaceutical industry (warts and all) will provide them. 